\title{
LENGUAJE INFANTIL E IMAGINARIO DE NIÑEZ EN LA SERIE PAPELUCHO DE MARCELA PAZ
}

\author{
Isabel Ibaceta \\ Universidad de O'Higgins \\ Rancagua, Chile \\ isabel.ibaceta@uoh.cl \\ Miguel Ramos \\ Universidad de O'Higgins \\ Rancagua, Chile \\ miguel.ramos@uoh.cl
}

\section{RESUMEN / ABSTRACT}

En este artículo abordamos la configuración de un lenguaje infantil en la serie de novelas Papelucho de Marcela Paz. A través de una indagación en los recursos literario-lingüísticos, evidenciamos una perspectiva enunciativa que subvierte el imaginario de niñez vinculado a lo lingüísticamente limitado, participando en el ámbito lingüístico del mundo adulto y tensionándolo. Esta apropiación se establece a partir del desdibujamiento y tránsito constante de la voz narrativa entre las dimensiones sémiotique y symbolique del lenguaje (Kristeva). Con este trabajo, buscamos aportar a la discusión sobre concepciones de niñez en la literatura, desde una aproximación que se sustenta en el análisis de la singularidad estética del lenguaje. Igualmente, esperamos contribuir a la exploración de una serie que representa un hito dentro de las producciones culturales del siglo xx en Chile.

Palabras clave: ficciones de lenguaje infantil, Papelucho, Marcela Paz, imaginarios de niñez, narrativa chilena del siglo XX. 


\section{CHILD LANGUAGE AND CHILDHOOD CONCEPT \\ IN MARCELA PAZ'S PAPELUCHO SERIES}

The current article addresses the configuration of child language in the Papelucho series (Marcela Paz), by examining different literary-linguistic resources used by the author, we find an enunciative perspective that subverts the traditional conception of childhood linked to a limited linguistic ability. Conversely, child language is validated through a process of playful linguistic appropriation, participating in the linguistic adult sphere and straining it. We see a narrative voice that constantly blurs and transit between the sémiotique and the symbolique language dimensions (Kristeva). This study contributes to the discussion about conceptions of childhood in literature, offering an approach focused on the analysis of an aesthetic singularisation of language, and based on a book series which is a milestone among the cultural production in Chile during the twentieth century.

KEYWORDS: children language fictions, Papelucho, Marcela Paz, concepts of childhood, twentieth century Chilean narratives.

Recepción: 04/03/2020 Aprobación: 11/04/2020

\section{INTRODUCCIÓN}

A partir del siglo XVIII se establece en Europa el concepto de infancia, diferenciándose de forma clara del ciclo de la vida adulta (Ariès 25-29). El desarrollo de este concepto es resultado, prácticamente, de un siglo de debates filosóficos relativos a la naturaleza de los procesos de aprendizaje de la mente humana ${ }^{1}$. Desde entonces, se erige en el mundo occidental una particular cultura de producción de bienes, servicios y políticas dirigidas específicamente a la niñez. Esta producción se verá nutrida, de manera importante, por las discusiones que emergen durante el siglo XIX en torno a las severas consecuencias que acarrea la consolidación del modo de producción capitalista, especialmente para la población infantil de sectores populares. En consecuencia, el siglo XX avistará un desarrollo, cada vez más importante, de estudios sobre la infancia en Europa y América (Rojas Flores, "Los niños" 3), desde muy diversas disciplinas (Mills y Mills 8), entre las que se cuenta la literatura.

1 Algunos trabajos fundamentales de este período son: An Essay Concerning Humane [sic] Understanding (1689), Some Thoughts Concerning Education (1693) de John Locke y el trabajo de Jean-Jacques Rousseau Émile ou de l'éducation (1762). 
Para el estudio de las nociones de niñez desde esta última disciplina, precisamos relevar la propuesta que hace Ariès a mediados del siglo XX, quien sostiene que la infancia no es solamente una etapa psicobiológica particular, sino que constituye una creación discursiva, histórica y geográficamente situada $^{2}(26-27,133)$. Al respecto, en el ámbito de los estudios literarios, se ha puesto en evidencia cómo las narrativas específicamente producidas para la niñez, consciente y/o inconscientemente, legitiman (o subvierten) las normas y estructuras sociopolíticas de las comunidades (Hollindale 3; Hunt 4; Zipes 67). Específicamente, se ha dado cuenta de cómo estas narrativas configuran un espacio cuya poética se desarrolla de manera estructural en torno a idearios de infancia (Rudd, "Theorising and theories" 25), los cuales establecen y normalizan concepciones hegemónicas o contrahegemónicas de lo que la niñez es o debiera ser y, por oposición, como ha planteado Vanessa Joosen, ciertas visiones sobre la misma adultez (10).

En el Reino Unido y Norteamérica, en la esfera de la literatura en general, se observa un desarrollo de trabajos enfocados específicamente en la configuración del lenguaje infantili3; pero solo a partir de la década de 1990 es que este tema se explora en literatura especificamente producida para la infancia. Estos abordajes, no obstante, no se centran mayormente en identificar/discutir los mecanismos que posibilitan la creación de un lenguaje infantil, sino que lo hacen desde un análisis de la construcción racial (personajes infantiles afrodescendientes) (Rahn 258) y desde la visibilización de la importancia del alfabetismo literario del personaje infantil (Myers 79).

En Chile, hasta donde sabemos, tampoco existen estudios de literatura para la infancia que tengan este enfoque ${ }^{4}$, aun cuando existen producciones

2 Hugh Cunningham señala que esta propuesta habría sido expuesta previamente por Norbert Elias, en su trabajo The Civilizing Process (1939).

En estas investigaciones, se analizan las estrategias utilizadas por escritores para articular ficciones de un habla infantil en narrativa, lírica y drama (Ricou 1987). Por otra parte, se problematizan las memorias de infancia de adultos/as, que se reconfiguran en el presente de la narración (Hurst 1990). Goodenough, Haberle y Sokoloff (1994) examinan personajes y voces infantiles en textos escritos para adultos, jóvenes y para/por niños/as. Este volumen tiene como eje la problematización de la voz de la niñez, en tanto registro siempre mediado por adultos/as.

Es necesario señalar que, en lo que respecta a la literatura para adultos en Chile, sí se observa un interés académico por la figura de la infancia desde aproximadamente los años 70. En lo referente específicamente al análisis de las voces infantiles, existen desarrollos críticos, principalmente, en las últimas dos décadas. En este período, encontramos trabajos 
literarias de alta relevancia cultural que ponen la voz y lenguaje del niño en el centro del relato. El ejemplo paradigmático: Papelucho. La serie de novelas de Marcela Paz, publicadas entre 1947 y 1974. Como indica el historiador Jorge Rojas Flores, esta es una de las producciones artísticas para la infancia más representativas del siglo $\mathrm{XX}$, cuya complejidad lingüística no ha sido explorada (Historia 592), así como tampoco las visiones de infancia en ella implícita. Es necesario señalar que la ausencia de abordajes del fenómeno lingüístico en la serie, se enmarca dentro de una falta más amplia de estudios en torno a la producción de Marcela Paz.

Antes de escribir las novelas de Papelucho, Marcela Paz ya había recibido atención de la crítica ${ }^{5}$ y premios de reconocimiento ${ }^{6}$. Con la publicación de la serie, este reconocimiento se reafirma categóricamente, lo que se plasma en la obtención de importantes galardones ${ }^{7} \mathrm{y}$ en el posicionamiento de la serie como verdadero fenómeno editorial, como consigna Bernardo Subercaseaux ${ }^{8}$. A esto se suma la ingente cantidad de ediciones ${ }^{9}$, traducciones ${ }^{10} \mathrm{y}$ adaptaciones ${ }^{11}$ que esta serie tiene a su haber. En contraste al reconocimiento y la popularidad, se observa un acotado cuerpo de estudios sobre estas novelas. Existen aportes

como los de Jeftanovic y Navia, Hablan los hijos: discursos y estéticas de la perspectiva infantil en la literatura contemporánea (2011) y de Amaro y Lange "Dossier: escrituras de infancia". Aisthesis 54 (2013).

En la década de 1930, su primer libro Tiempo, Papel y Lápiz (1933) es elogiado por Hernán Díaz Arrieta (Alone) y Amanda Labarca (Ibaceta, "Más allá de Papelucho" 6).

Premio Sanidad por Pancho en la luna (1927). Premio Club Hípico (1934) por Ensayos para un concurso. Este volumen se publica en 1935 como Soy colorina (Ed. Ercilla).

Premio de Honor de la Editorial Rapa-Nui (1947), Premio Office Chrétien du Livre, Paris (1980), Premio Nacional de Literatura (1982), entre otros.

$8 \quad$ En la década de 1950 se vendían cuatro mil trescientos ejemplares anuales de Papelucho (1947), mientras que el tiraje normal de un libro en este periodo no excedía las mil copias (150-55).

9 Se estima que las ediciones de la serie superan las 400. Fuente: http://www. memoriachilena.cl/

10 Existen traducciones al francés, japonés, italiano, griego y alemán. Además, hay disponible una traducción bilingüe: español-inglés y una versión en braille. Fuente: sitio web de la Fundación Marcela Paz http://www.papelucho.cl/

11 Existen adaptaciones de algunos títulos al cine, a las historietas, al teatro, a la ópera. Incluida una adaptación para personas con problemas auditivos en: http://papelucho.cedeti. $\mathrm{cl} /$ 
relevantes desde la historia del libro ${ }^{12}$ y ciertos alcances pertinentes desde producciones biográficas ${ }^{13}{ }^{14}$. Nos interesa relevar la exploración desde la historiografía de la infancia que hace Jorge Rojas Flores, quien se percata de que Papelucho (1947) sería una de las primeras narrativas que intenta la construcción discursiva de una voz y perspectiva infantil ${ }^{15}$. Rojas, además, identifica los discursos sobre sindicalismo e inequidades sociales. También contrasta las relaciones familiares en la serie con patrones de crianza en la década de 1960 y 1970. Finalmente, releva la riqueza y complejidad lingüística (Historia 590-592); a cuya exploración esperamos aportar en este trabajo.

En el ámbito académico, desde los estudios literarios, se encuentra un reducido número de trabajos. Estos son los de Cifuentes e Ibaceta. Esta última examina la construcción de imaginarios de infancia desde un enfoque centrado en la articulación discursiva del cuerpo infantil, que dialogaría con lo abyecto y el realismo grotesco ("El cuerpo del niño" 6-15). Cifuentes, por su parte, explora diversos mecanismos humorísticos en base al concepto de humor leve de Ítalo Calvino. Estos mecanismos permitirían "una conciencia y una forma de conocimiento del mundo alternas", que harían posible presentar, a la potencial audiencia infantil, la compleja realidad de forma menos drástica ("Marcas discursivas" 31). Cifuentes luego profundiza en las interrelaciones entre humor y el sentido de angustia como elementos estructurales en la serie. Postula que las novelas brindarían un espacio para enrostrar la angustia, posicionándola en un espacio de menor amenaza. Es decir, así como los cuentos de hadas enfrentarían a los lectores con los problemas de manera simbólica, la serie, a través del humor, permitiría enfrentar la realidad desnuda, desde un prisma de distensión, que balancearía la crudeza de la realidad con

12 El trabajo de Manuel Peña es, principalmente, biográfico. Sobre la serie, aporta observaciones generales que dan cuenta de una crítica a las formas de crianza y a la desigualdad social en Chile (143-159).

13 Se han publicado dos libros de corte biográfico. El más reciente, de Ana María Larraín se aproxima a la serie desde una visión muy general y descriptiva (14-16). El texto de Virginia Cruzat, por su parte, busca aunar las experiencias de Papelucho con vivencias personales de Paz (92-96).

Es relevante también mencionar un artículo de prensa de Alberto Fuguet, quien desmitifica a Papelucho en tanto cliché de alegría y bondad, pone de manifiesto las complejidades narrativas e ideológicas de la serie, atisba los fenómenos del doble destinatario (infantil y adulto) y de la configuración de una figura pública de Papelucho, como ícono de la cultura popular chilena (18-22).

15 Antecedido por el Niño que enloqueció de amor (1915) de Eduardo Barrios. 
lo ridículo y jocoso que acompaña, en general, a toda situación angustiante ("Angustia y humor" 131-139). Estos estudios representan un avance en el campo literario. No obstante, la dimensión lingüística, los mecanismos de configuración de una voz infantil y las concepciones de infancia en la serie, permanecen aún poco exploradas.

En consecuencia, el objetivo de este artículo es identificar los mecanismos literario-lingüísticos (observados transversalmente a lo largo de la serie) que permiten la ficcionalización de un lenguaje infantil en la serie Papelucho y que ponen de manifiesto, a su vez, un particular imaginario de niñez. Buscamos observar cómo esta habla da pie a la sensación de una consciencia no adulta. La representación de la consciencia en la literatura ha sido fundamental en el desarrollo del género de la novela occidental (Cohn 7-9). No obstante, en la literatura para la infancia en Europa y Norteamérica, el giro desde la narración de eventos hacia un interés en representar pensamientos se desarrolla visiblemente solo a partir de 1980 (Nikolajeva, Imprints 173). Las novelas de Papelucho son frecuentemente referidas como relatos de aventuras, sin profundizar en su nivel de introspección y su relación con el lenguaje; relación que revela la presencia de una mente ficcionalmente infantil.

Para cumplir con el objetivo de este trabajo, examinamos las doce novelas que conforman la serie ${ }^{16}$, principalmente en sus primeras ediciones, para evitar la incorporación de versiones actuales que han sido alteradas léxica y sintácticamente (Rojas, Historia 592). En nuestro análisis de las obras, el cual no asume un enfoque estructural tradicional, identificamos diversos recursos literario-lingüísticos que situamos en categorías que facilitan su exposición. En primer lugar, abordamos una hipervisibilización del registro oral, luego, nos abocamos a la articulación de la dualidad entre conocimiento y desconocimiento desde la dimensión léxico-semántica. Posteriormente, trabajamos en torno a mecanismos lexicogenésicos y fraseológicos. Para terminar, atendemos a la dislocación morfosintáctica que afecta, entre otras relaciones lógicas, al sentido de coherencia de párrafos y oraciones. Es importante señalar que las distintas dimensiones de la lengua que observamos (i.e., lo léxico, morfosintáctico, fraseológico, semántico y pragmático) se

16 Ver listado de las novelas en bibliografía. No abordamos las novelas póstumas Papelucho, Romelio y el castillo (2018), Adiós planeta por Papelucho (2018), pues para su estudio se requeriría indagar en su proceso de edición a partir de los borradores que dejó Marcela Paz. 
interrelacionan y no son totalmente separables, aun cuando demos cuenta de ellas en apartados distintos.

La centralidad que otorgamos a las particularidades lingüísticas dice relación con la necesidad de no obliterar la atención a la forma en la apreciación del arte, como propone Susan Sontag (27). Bajo esta perspectiva, reafirmamos el hecho de que es a través de la singularidad de la textura de la palabra, que el discurso literario conforma su peculiaridad estético-ideológica.

\section{DESAFIANDO EL IMAGINARIO DE HABLA INFANTIL: DE SITIO DE LIMITACIÓN A ESPACIO DE PODER Y CREACIÓN}

En la serie de Paz, la sensación de consciencia se establece a través de una operatoria humorística y lúdica que contrasta un manejo lingüístico inacabado y confuso por parte del niño y un supuesto pleno dominio, característico del desempeño lingüístico adulto, en su variante más estandarizada. En este contraste se pueden observar binarismos histórica y culturalmente establecidos, tales como lo correcto/incorrecto, lo completo/inacabado, lo racional/irracional, los cuales han situado el habla infantil en un espacio marcado por la insuficiencia y el error. Veremos, no obstante, que el trabajo de Paz tensiona y desborda tales binarismos.

De acuerdo con Goodenough et al., el imaginario de lenguaje infantil asociado a la carencia y al error se remonta al siglo XVII. No es coincidencia, según estos/as autores/as, que el término establecido durante el siglo XVIII para denominar esta etapa vital (infancia), provenga de un cognado latino que significa "incapaz para hablar" (3). Esta visión de infancia se nutrió de perspectivas que planteaban que el aprendizaje del lenguaje constaba en adquirir y dominar un conjunto de reglas que se creían instaladas en la estructura cerebral (Wells xvii). A partir de desarrollos realizados en áreas como la psicología y la fisiología, esta idea se reforzó. En el desarrollo de la teoría de la célula, por ejemplo, en el siglo XIX, se usa la imagen del crecimiento infantil como analogía del desarrollo celular, como plantea Rudd (Reading 7). Según este autor, la niñez fue también un ícono para representar las teorías del inconsciente, establecidas por Sigmund Freud a comienzo de los años 20 (Reading 8). Posteriormente, Lacan se centra en la figura del niño para caracterizar uno de los órdenes de la psique humana. El orden Imaginario, asociado a la dimensión preverbal del sujeto, donde prima lo irracional e instintivo, en oposición al orden Simbólico, marcado por el entendimiento 
y aceptación por parte del sujeto de la convencionalidad de los códigos lingüísticos, que establecen la normatividad del ordenamiento social (67).

Todo lo planteado anteriormente pone de manifiesto que, en las sociedades occidentales adultocéntricas, se ha establecido la idea de una infancia asociada a la insuficiencia y a lo subdesarrollado, en oposición a una supuesta integralidad lógica y racional propia del lenguaje adulto. En las novelas de Paz se visualiza una perspectiva enunciativa que problematiza y des-esencializa esta visión. En ellas, el error y la confusión son parte de una relación lúdica y creativa con el lenguaje, que pone de manifiesto la inestabilidad del significado como algo propio de la naturaleza de toda lengua, en tanto sistema de símbolos en cuyos márgenes la subjetividad de los y las hablantes es irreductible.

En la serie, la puesta en escena de un lenguaje que se despoja conscientemente de las amarras normativas de la lengua permite poner en diálogo el trabajo de Paz con las ideas de Julia Kristeva. Esta última, entiende el lenguaje como fenómeno que se constituye, por una parte, por una dimensión sémiotique, en donde la unidad de la significación se desdibuja, se abre a la indeterminación, rigiendo sobre ella la musicalidad en vez de la regulación sintáctica de los sistemas de signos (18). Por otra parte, por una dimensión asociada a la función symbolique. Aquella dimensión -en consonancia con los postulados de Lacan- que busca la unitariedad, la fijación de la significación y la búsqueda de la homogeneidad de los lenguajes nacionales, por medio de las reglas gramaticales (Kristeva 17). Es en un diálogo entre estas dos dimensiones que se establece un lenguaje infantil en la serie de Paz. Este diálogo se configura y tensiona por medio de una voz narrativa en primera persona, cuyas particularidades literario-lingüísticas permiten la articulación de un sentido de lenguaje y consciencia infantil. Una primera particularidad dice relación con la ficcionalización de la oralidad, la cual abordamos a continuación.

\section{RECURSOS LITERARIO-LINGÜÍSTICOS EN LACONFIGURACIÓN DE UN LENGUAJE INFANTIL EN LA SERIE}

La creación del lenguaje en la serie se funda en la ficcionalización de una consciencia infantil que se establece, en primer término, sobre una voz que identificamos como un "dramatized, agent [and] self-conscious narrator" (Booth 149 -165). Es decir, una voz protagónica (dramatized), que narra eventos en los cuales participa (agent) y que se reconoce a sí misma como 
creadora del texto narrativo (self-consciouss). Este último elemento es posible gracias a la estilización literaria del género referencial del diario íntimo ${ }^{17}$. A través de este tipo de narrador, se construye una voz infantil fuertemente vinculada con el registro oral y rica en recursos literario-lingüísticos variados que buscan alejarse de los usos normativos de la lengua.

La creación de un sentido de oralidad y su vinculación con el lenguaje infantil en la serie se logra explotando aquella perspectiva histórico-ideológica que plantea la superioridad de la comunicación escrita sobre la oral ${ }^{18}$. En esta línea, la capacidad lingüística de niños y niñas se sitúa en esta esfera menor, puesto que vivencian un espacio predominantemente oral hasta su ingreso al sistema escolar (Wells xix), a pesar de estar rodeados por la escritura desde su nacimiento. Sin embargo, problematizamos la perspectiva ideológica respecto de la subvaloración de la oralidad puesto que en la serie de Paz vislumbramos la construcción de un habla infantil que subvierte esta posición por medio de la celebración y el protagonismo con que se dota al lenguaje oral.

Adicionalmente a la ficcionalización de la oralidad, los recursos literariolingüísticos que dan pie a un lenguaje infantil operan incorporando instancias de habla que emplazan al niño en una zona de dualidades tensionadas. Lo posicionan, de manera lúdica (por medio del humor verbal de tipo incongruente y la ironía estructural, a las que nos referiremos más adelante) entre el conocimiento y la ignorancia, entre la claridad y la confusión, entre la ingenuidad y la sagacidad, entre lo correcto y lo supuestamente irregular.

17 Diez de las doce novelas de la serie son textos en formato de diario íntimo. Existen dos de ellas que no permiten advertir que el relato esté enmarcado dentro de la ficción del género referencial.

18 Esta perspectiva, enraizada en la cultura occidental, es de larga data y ha sido abordada por diversos/as académicos/as. Representativo de sus aproximaciones es el trabajo de Ong $(44,46)$. No obstante, a esta perspectiva de inferioridad de lo oral, se contraponen lingüistas como M. Halliday. Este autor indica que, en culturas alfabetizadas, el lenguaje escrito tiende a poseer una mayor valoración social porque muchas de las funciones de más alto prestigio social se realizan a través de la escritura, restringiendo el lenguaje oral a funciones consideradas de menor valor. Se transmite así el mito del lenguaje hablado como una forma inferior, incluso sin forma ni estructura lógicas. Sin embargo, plantea que ambas tienen sus propias complejidades y demuestra que el lenguaje oral presenta una mayor complejidad gramatical, aunque una menor densidad léxica (Comprehending 61; Spoken 63). 
2.1. HiperVisibILIZACIÓN DEL REGISTRO ORAL: DESMARQUE DE LA NORMA LINGÜÍSTICA Y VINCULACIÓN CON EL ENTORNO SOCIAL

El sentido de la oralidad se construye en la serie de Paz gracias al accionar de diversos elementos tales como el uso de expresiones coloquiales y la referencia a variedades sociolectales, la inclusión de una parataxis acentuada y la recurrencia en la incorporación de interjecciones. A continuación, mostramos estos elementos de oralidad presentes en la obra.

\subsubsection{Papelucho jerguístico: el acervo lingüístico popular chileno}

El lenguaje coloquial se entiende como una forma comunicativa eminentemente oral, aun cuando pueda eventualmente entrar en la esfera escrita. Al respecto, Bajtín indica que lo coloquial se estiliza literariamente cuando emerge el género de la novela, momento en el cual las expresiones cotidianas ingresan a la creación artística (98).

Las obras que componen la serie de Paz son construidas eminentemente sobre vocablos y expresiones del lenguaje cotidiano popular chileno. Los ejemplos son múltiples en cada una de las novelas de la serie. Exponemos aquí, a modo de ilustración, dos ejemplos de cada una de ellas:

Papelucho: guacho (solo) ${ }^{19}$, boche (problema, discusión) $(22,12)$; Papelucho casi huérfano: clotió (estropeó), pituco (arrogante, de clase social alta) (23, 35); Papelucho historiador: puro carril (solamente cuentos) puñete (golpe de puño) $(31,32)$. Papelucho Detective: guaguas (bebés), callampa (población de la periferia) (34, 26); Papelucho en la clínica: color de hormiga (complejo), tirar pinta (verse bien) (14, 53); Papelucho perdido: pescuezo (cuello), patas (pies) (11, 60); Mi hermana Ji por Papelucho: pa callao (secretamente), cantoras (bacinicas) (23, 27); Papelucho misionero: hagan la pata (adulen), choriflai (estupendo) $(15,53)$; Diario secreto de Papelucho y el marciano: choros (astutos), guanaco (carro lanza agua) (17, 45); Papelucho en vacaciones: cabros (niños), empiluchamos

19 Entre paréntesis ofrecemos términos del registro no coloquial a los cuales se estaría aludiendo en las páginas citadas. Es importante remarcar que estas expresiones, por supuesto, pueden variar en su carga semántica dependiendo del contexto de las oraciones en las cuales se les utilice. Por ejemplo, es de conocimiento general que guachos también ha designado, despectivamente, a los huérfanos. 
(desnudamos) (9, 41); Papelucho mi hermano hippie: sacándome pica (incitándome a la envidia), me cayó la teja (me di cuenta) (18, 69); Soy dix leso? Por Papelucho: lolos chascones (jóvenes de pelo largo), a todo chancho (a toda velocidad) $(17,34)$.

Una buena parte de la creación de estas palabras o frases idiomáticas se relacionan, además, con la ficcionalización de voces provenientes de diversos sectores socioculturales. El lenguaje novelístico incorpora expresiones orales de esta diversidad sociolingüística del contexto de producción. Esta inclusión es lo que Bajtín denomina el lenguaje social dialógico, el cual sería una respuesta a la imposición homogeneizadora de los lenguajes nacionales, en tanto buscaría visibilizar las hablas cotidianas (Bajtín 87, 96).

En las novelas analizadas, la configuración lingüística social dialógica o variedades sociolectales, que proponemos busca visibilizar el lenguaje oral, informal e históricamente situado, se establece a través de la construcción del habla de personajes pertenecientes a diversos estratos socioeconómicos. Ejemplo de aquello es la figura de la empleada doméstica, Domitila (que viene del campo), además de obreros de la construcción, mecánicos, profesores, diputados, indigentes y pobladores de las "callampas". Reproducimos un diálogo de estos últimos, a continuación:

-Ella le dio un coscacho en la cabeza y lo insultó.

-Pelusa...que te llevay palomillando en vez de hacer lo que te mandan -le dijo.

-Pero si juí onde me dijo -alegó Chirigüe.

- ¿y cuál es que lo trajiste?

-Pero si no staba $[$ sic $]$ el julano...

- ¿Y quién te manda a ponerte a jugar con este pijecito? (Papelucho detective 11)

Esta escena se desarrolla cuando Papelucho acompaña a su amigo Chirigüe a la población de la periferia santiaguina en donde este niño habita. El desplazamiento físico de Papelucho se sirve de la técnica episódica del viaje, propio del relato picaresco, el cual le permite ingresar a espacios poblados de lenguajes que difieren de aquellos presentes en su entorno social más cercano. En estos espacios, con ojo crítico, actúa como testigo de la inequidad social y, con agudeza, vislumbra y hace suyas, a la vez, otras realidades lingüísticas. La instalación de un narrador observador e ingenuo, a través del cual se transmite una crítica social implícita, es lo que se ha denominado ironía estructural (Frye 89, Colebrook 14). 
La exposición de la diversidad sociolectal muestra que, si bien Papelucho tiene un manejo lingüístico cruzado por la inmediatez de lo oral, a lo cual se suma la parataxis y las interjecciones, como veremos a continuación, posee, no obstante, una sagacidad para relacionarse, comprender y reproducir la jerga coloquial propia de su entorno.

\subsubsection{Papelucho paratáctico: el (sobre)uso de la conjunción coordinante copulativa ' $y$ '}

Otro de los recursos literario-lingüísticos que se aprecia frecuentemente en las novelas estudiadas es la sobreutilización de la conjunción coordinante copulativa ' $y$ '. Hablamos, en este caso, de utilización reiterada no solamente por el hecho de aparecer con alta frecuencia en los relatos de Papelucho, sino especialmente porque se incorpora en contextos donde, desde perspectivas normativistas, se aconsejaría no usarla o bien no sería necesaria su integración. El insistente uso de lo señalado dota a los enunciados de una particularidad rítmica ${ }^{20}$ y de una estética singular, que evoca ciertas características de la expresión oral. Los ejemplos que se entregan a continuación grafican este fenómeno. En negrita y subrayadas se destacan aquellas conjunciones coordinantes 'y' que, desde un punto de vista sintáctico y semántico podrían haberse sustituido por otro tipo de elementos de enlace, o bien no requerían insertarse obligatoriamente.

(...) pero yo estaba ensayando mi honda nueva $y$ como el Tuerto ni siquiera ve, creyó que la piedra que disparé le había pegado a él, $\boldsymbol{\nu}$ se espantó $\underline{\underline{ }}$ salió disparado con coche y todo $\underline{\boldsymbol{y}}$ quebró la lanza $\underline{\boldsymbol{}}$ atropelló la puerta cochera $[\mathrm{sic}] \boldsymbol{\boldsymbol { }}$ la arrancó de quicio que es muy embromado, dicen, $\boldsymbol{y}$ también sacó las dos ruedas del coche (Papelucho casi huérfano 40-1)

(...) La cuestión fue que poco a poco se armó un enredo \ la luna era el Hospital y los médicos eran enemigos $\mathbf{y}$ nos tomaban presos y todo lo demás. $\underline{\mathbf{Y}}$ yo trataba y trataba de despertar $\mathbf{y}$ era inútil y resulta que me había convertido en estatua igual que el caballero de bronce que hay a la entrada del H (Papelucho en la clínica 43). 
En los ejemplos anteriores, se hace evidente el uso desproporcionadamente frecuente de la coordinante copulativa ' $y$ ' como mecanismo de cohesión discursiva estableciendo relaciones de índole sintáctica y semántica. El uso de la coordinante ' $y$ ' establece una relación no jerárquica entre los elementos enlazados, lo que la hace distinta de elementos que permiten la subordinación, integrando contenidos dentro de otros, categorizándoles. Con secuencias como las expresadas en los extractos antes expuestos se transmite la idea de estar en presencia de un hablante que aún no es plenamente capaz de categorizar, de distinguir, de discriminar lo importante de lo accesorio, de establecer enlaces de orden jerárquico, estructurando un relato por medio de relaciones más complejas entre los elementos que integran en el discurso.

Es interesante notar, además, que este uso desproporcionado de ' $y$ ' se potencia con la integración de expresiones formulaicas, secuencias prefabricadas y convencionalizadas, de dos o más palabras (Bybee 35-36). Ejemplo de esto se observa en expresiones tales como 'y todo', 'y resulta que', entre otras. En estos casos, la ' $y$ ' no tiene la función de enlazar elementos. Sumados ambos usos de ' $y$ ', se consigue un alto nivel de redundancia de este término.

Por último, en la serie se construye un sentido de oralidad por medio del uso de interjecciones que serán materia de la siguiente sección.

\subsubsection{Papelucho onomatopéyico: interjecciones}

El estatus propiamente lingüístico y la categorización precisa de las expresiones onomatopéyicas han sido objeto de debate permanente, de larga data. Algunas veces incluidas dentro de la categoría de interjecciones (Tesnière 99); en otros análisis, y dado que no cumplen la función de expresar el estado mental del hablante como sí lo hacen las interjecciones, aparecen como una categoría separada (Stange 16-17). En este sentido, dichas producciones imitan ruidos o sonidos del entorno (no humano), tales como sonidos animales o aquellos causados por el movimiento de ciertos objetos o por eventos particulares. En la serie de novelas de Paz, es habitual el uso de estas expresiones por parte de Papelucho, encontrándose numerosos ejemplos como los que se presentan a continuación:

-y iprum! Se quebró el gancho en que se sostenía y se vino al suelo estrepontosamente [sic]-(Papelucho en vacaciones 19). 
Por eso seguí pensando en la Comisaría y hasta en el calabozo, cuando ¡¡ZZAZZ!! ¡PRUM! ¡CHUKZAZ! Chocamos” (¿Soy dix leso? por Papelucho 22) ${ }^{21}$.

El uso de onomatopeyas no es, en absoluto, privativo del lenguaje infantil; sin embargo, son particularmente frecuentes durante los primeros años de vida, en distintas lenguas (Vihman 160-161). No obstante, a pesar de este dato, para los propósitos de este análisis resulta interesante relevar aspectos relacionados con las funciones y efectos de su uso.

En el caso de los ejemplos anteriores, Papelucho nos entrega una batería de efectos de sonido que hacen más gráfica y vívida la escena descrita; decorando y enriqueciendo su relato, proporcionándole un toque de realismo mayor, potenciando la creación de la atmósfera pretendida y haciendo que los sonidos del mundo circundante entren con libertad en esta esfera. En el primer ejemplo, Papelucho utiliza la onomatopeya prum para dar cuenta del momento en que se rompe un gancho, provocando una caída; mientras que, en el segundo ejemplo, utiliza tres onomatopeyas distintas para dar cuenta de un accidente que implica varios golpes sucesivos. Dichos golpes son evocados por medio de cada onomatopeya.

Por otra parte, resulta evidente que el uso de estas expresiones dota de un carácter oral al relato del niño, en cuanto trastoca los márgenes que tradicionalmente tienden a dividir lo oral de lo escrito. En este sentido, al tratarse de elementos que aparecen en el discurso de forma más bien espontánea, se perciben como ajenos al registro escrito, espacio donde la elaboración planificada es una característica que tiende a predominar de manera particularmente marcada. Su inclusión en los relatos supone así una nueva transgresión, por parte de Papelucho, de los límites del discurso escrito y hablado.

Sumado a la ficcionalización del registro oral, el lenguaje infantil se crea por medio de recursos tales como el desconocimiento y confusión de términos por parte del niño-narrador, elementos que exponemos a continuación. 
2.2 DESCONOCIMIENTO Y CONFUSIÓN COMO REVELADORES DEL SABER: DIMENSIÓN LÉXICO-SEMÁNTICA

La ficción del desconocimiento léxico-semántico se visualiza en numerosas ocasiones en que el narrador-escritor indica explícitamente que no entiende el significado de ciertas palabras o expresiones. Asimismo, es implícitamente perceptible la ficcionalización de problemáticas que se ubican en esta dimensión, cuando la voz narrativa deja al descubierto que el niño no comprende, o tiene nada más que cierta intuición respecto del significado de algunos términos. Dichas expresiones y términos son aquellos que, generalmente, pueden identificarse como no coloquiales. Señalamos dos ejemplos de cada novela aquí:

Papelucho: acontecimientos, consecuencias (48, 62); Papelucho casi huérfano: conyugal, presentimiento (27, 40); Papelucho historiador: cadena de montañas, asamblea (17, 72). Papelucho detective: pérdida, bautizo $(45,48)$; Papelucho en la clínica: ver candelillas, trastornado (16, 49); Papelucho perdido: ser una perdida, diputado (9, 23); Mi hermana Ji por Papelucho: tizne, evasión (13, 22); Papelucho misionero: repercutió, enunciación (24, 33); Diario secreto de Papelucho y el marciano: impotente, kilates (43, 24); Papelucho en vacaciones: exiliados, oneroso (31, 54); Papelucho mi hermano hippie: putrefacta, madurez $(9,54)$; Soy dix leso? por Papelucho: erótica, quirófano $(10,23)$.

En el caso de Papelucho detective, por ejemplo, el término "pérdida", se utiliza en un contexto que hace referencia a una situación de riesgo del embarazo de la madre de Papelucho. El niño, no obstante, entiende el significado de dicho término, solo en una de sus acepciones (perdida = extraviada). De ahí que llegue a señalar que no comprende cómo se puede perder una hija en un dormitorio tan pequeño (45). En lo que respecta a la palabra "erótica", en Soy dix leso? por Papelucho, es evidente que el niño reproduce la opinión de su padre de manera abierta, dado su desconocimiento del significado de este término. El padre, según Papelucho, señala que la profesora es una "erótica y calumnienta" cuando indica que Papelucho tiene una condición de dislexia (10). El desconocimiento o relativo desconocimiento de términos, tal como en el ejemplo anterior, se manifiestan por medio de una confusión entre términos que portan similitud tanto en las propiedades rítmicas como en los fonemas que les constituyen (presencia de rima), un rebelde juego con la morfología de las palabras (rompiendo sus morfemas constitutivos) y una sutil 
pero sofisticada provocación semántica al usar el término "erótica". Cuando se confronta esta palabra con el contexto situacional al que hace alusión este adjetivo, deducimos que la palabra usada por el padre de Papelucho es, muy probablemente, "neurótica". Más ejemplos de este tipo de reemplazo léxico son "magnesia" por amnesia en Papelucho en la clínica (15) y "sub-gerencia" por "sugerencia" en Papelucho Misionero (19), entre otros.

La confusión o desconocimiento léxico-semántico sitúa al narrador-niño en una condición de diferencia respecto de un/a hablante adulto/a ideal, cuya amplitud y profundidad del conocimiento léxico se supone mucho mayor. Se construye, así, la sensación de estar frente a un hablante que posee una competencia comunicativa diferenciada, que se desenvuelve con mayor propiedad en el ámbito del lenguaje coloquial, como se mostró en la sección previa.

El ficcionado desempeño lingüístico que da cuenta de un conocimiento léxico de menor amplitud respecto del saber adulto (la madre y el padre en los ejemplos anteriores), se articula desde la estrategia del humor verbal. Esta forma lúdica se puede entender desde las teorías de la incongruencia. De acuerdo con Morreall (1989) y Forabosco (1992), estas plantean que el efecto humorístico se produce cuando algo inapropiado, ilógico o inesperado es percibido por un sujeto, siendo ampliamente incongruente con la expectativa de lo que este esperaba escuchar, leer o presenciar (Cit. en Cross 7). Esto es lo que vemos claramente cuando aparece la palabra "erótica" en un contexto de situación en el cual se advierte totalmente disparatada ${ }^{22}$.

La aproximación desde esta vereda lúdica vuelca la atención hacia la complejidad de la comunicación y la comprensión entre sujetos, sin poner el acento en la necesidad de aprender o de enmendar las formas comunicativas utilizadas por el niño. Al contrario, la aparente poca amplitud léxica del infante se desdibuja al contrastarse con su sagaz e ingeniosa apropiación del lenguaje. Evidencia de ello es la presencia de mecanismos lexicogenésicos, los cuales instituyen un hablante seguro, versátil y altamente creativo.

22 Esto nos remite al fenómeno del direccionamiento dual: tanto hacia niños/as como hacia adultos/as a la vez (Wall 35); fenómeno que requeriría abordarse en un trabajo dedicado específicamente a ello. 


\subsection{LEXICOGÉNESIS Y FRASEOLOGÍA PAPELUCHÍSTICA}

Maria Nikolajeva ha indicado que en la literatura para niños es frecuente el uso de "nonce words". Estas son palabras acuñadas por escritoras y escritores que, si bien no son parte del repertorio oficial de la lengua, por su similitud con dicho repertorio, pueden comprenderse claramente (Aesthetic 206). Podríamos agregar, parafraseando a Crystal, que se trata de formas lingüísticas que cualquier hablante crea, consciente o inconscientemente y que, en algunos casos, llegan a ser adoptadas por la comunidad (329). El fenómeno mismo de creación de nuevas palabras se denomina lexicogénesis.

Ejemplos de esta capacidad creativa abundan en los textos de Papelucho. Una clara muestra de aquello se encuentra en Papelucho misionero, novela en que el narrador señala: "Da como miedo de que lo alaben tanto y de repente lo vayan a desalabar (...)" (25). La palabra "desalabar", si bien no figura en diccionarios es, sin embargo, totalmente comprensible, puesto que hay una clara lógica en su constitución, a partir de la combinación de elementos de significado perfectamente identificables. El término se construye a partir del lexema alab-(de la forma verbal alabar) a la que se añade el prefijo de negación 'des-', el que comúnmente se entiende con un efecto de reversibilidad. En consecuencia, el narrador-niño reconoce que su incorporación resulta en una inversión del significado base del verbo en cuestión. Este reconocimiento denota un manejo de mecanismos de formación y creación de palabras; entre ellos, la derivación. Así, resulta evidente en las novelas de la serie, el elevado dominio que tiene Papelucho para manipular y crear términos, además del acabado conocimiento de las reglas fonotácticas que estructuran las palabras en español. Bien vale revisar otros ejemplos que reflejan esta desbordante capacidad creativa. En este sentido, forma verbos nuevos a partir de adjetivos, es decir realiza procedimientos de verbalización adjetival, como se aprecia en la siguiente oración extraídas de Papelucho perdido: "Por primera vez me pareció linda la guagua. Era su felicidad que la boniteaba" (35).

De la misma manera, se observa en Mi hermana Ji por Papelucho un relato acerca de una discusión entre los amigos de Papelucho en los siguientes términos: "El Jolly se insolentó con los Ulloas. (...), los Ulloas se enfuriaron (...)" (32). En este ejemplo, podemos observar un caso de verbalización denominal (creación de un verbo a partir de un sustantivo: furia). Forma novedosa, en vez de 'enfurecieron'. Adicionalmente, encontramos en los textos, lúdicos casos de adjetivación denominal (adjetivos creados a partir de sustantivos), como apreciamos en esta oración "Hacía un calor africano y un hambre chileno y una sed elefántica (...)" (Papelucho misionero 46). 
Las incursiones exploratorias del niño en el uso lingüístico también se extienden a la esfera creativa, en tanto inventa términos que pueden operar como sustantivos y adjetivos. Estos pueden ser comprendidos, en la mayoría de los casos, por su relación sintagmática dentro de la oración y por el contexto que le entrega el tema y acciones del relato, como puede verse a continuación: "La oscuridad mojada se la estaba capeando la Ji en su canasto con una tapa de olla en la cabeza. Pero nosotros los grandes, teníamos tilimbre en todo el cuerpo" (Papelucho en vacaciones 16). La palabra "tilimbre" puede comprenderse, en el contexto de la situación dada, como una especie de temblor o escalofríos del cuerpo. Algunos otros ejemplos, que se encuentran en varios títulos de la serie, son: "chirimpoya" (término cuya función busca calificar una situación positivamente), "furiondo" (enojado) y "cataclípticamente" (especie de adverbio que califica una situación estruendosa, de grandes proporciones, y/o altamente atractiva y excitante).

Por otra parte, con respecto a la construcción de pluralidad, se observa una sobregeneralización en el uso del alomorfo plural 'es' como en los siguientes ejemplos: "muchos álguienes se carcajeaban" (Papelucho en vacaciones 54) y la referencia a las "mamáes" (Papelucho detective 42) y "papáes ancianos" (¿Soy dix leso? por Papelucho 13).

Sumado a lo anterior, en las novelas de Paz se encuentra una serie de creaciones surgidas a partir de recurrentes y peculiares transformaciones de expresiones idiomáticas que forman parte del acervo lingüístico popular. Estas expresiones son definidas como unidades gramaticales, idiosincráticas en cierto sentido, más largas que una palabra (Croft y Cruse 230). Es frecuente ver cómo el narrador-niño rompe con las convencionalidades propias de este tipo de construcciones, las reanaliza, deconstruye su unidad, transformando dichas expresiones por la vía de cambiar elementos léxicos de una unidad que supondría ser fija. Tal es el caso de a lo mejor, cuyo significado convencionalizado es quizás, que Papelucho convierte en su opuesto a lo peor. Este caso particular se da cuando Papelucho está en la disyuntiva de contarle a Domitila que habría sido envenenada con un sándwich, pues con tal noticia "a lo peor se moría del corazón" (Papelucho 8). Es interesante el reanálisis que hace de la construcción puesto que, ante una consecuencia tan radicalmente negativa, no hay espacio para una palabra como mejor. Encontramos, adicionalmente, en varios de los títulos de la serie, expresiones tales como: "no tengo ni la mayor idea" (en vez de ni la menor idea), "gritar a todo riñón" (en vez de a todo pulmón), "por si las pulgas" (en vez de por si las moscas). 
A través de la creación de este tipo de expresiones idiomáticas se configura un hablante menos constreñido por las disposiciones y normas lingüísticas que, según Pierre Bourdieu, rigen el desempeño de las prácticas lingüísticas (19). En este caso, se trataría de una convención establecida, más bien, de manera espontánea, por parte de comunidades de hablantes que han construido y transmitido estas expresiones de generación en generación, rescatando y preservando una sabiduría popular. No obstante, el niño igualmente rompe con el uso común e instaura sus propias versiones de las expresiones populares. En los ejemplos expuestos en esta sección distinguimos, justamente, un uso vinculado de manera importante con lo contextual, alejándose de la dimensión arbitraria de la lengua. Conjuntamente, observamos también un efecto humorístico del tipo incongruente.

\subsection{DislocaCión MORFOSINTÁCTICA: TRANSGRESIONES PAPELUCHESCAS}

Elementos adicionales que favorecen la conformación de un lenguaje infantil, en oposición a las lógicas ideales de un habla adulta, dicen relación con la articulación de párrafos y la conexión entre ellos, así como con la organización de frases y oraciones.

Con respecto a la organización de los párrafos, se distingue una secuencialidad que quiebra el ordenamiento lógico deseado en el escrito de un adulto. Es pertinente recordar que el habla de Papelucho es a la vez una escritura ficcionada a través del género referencial, razón por la cual la contrastamos con formas de escribir adultas.

En algunas anotaciones que Papelucho hace en su diario, observamos un desmarque del ideal de organización de los modos discursivos descriptivos, los que suelen, cuando hay enumeraciones, establecer coordenadas lógicas. Dentro de ellas, se sitúa la coordenada de lo general a lo particular, así como aquella del todo que luego se mueve hacia las partes (Calsamiglia y Tusón 281). En la anotación del diario de Papelucho (1947) se obvia o subvierte parcialmente este tipo de ordenamiento. Se integra en el cuerpo de un mismo párrafo información muy variada que no presenta conexión lógica entre ella. De esta forma, la anotación del diario, relativa al $1^{\circ}$ de enero, incluye temas sobre el envenenamiento de la empleada, sobre la santidad y las oraciones, sobre el año nuevo, declaraciones metaficcionales sobre la escritura del diario, descripción de un experimento, referencia a los bienes (corbatas) del padre y, finalmente, un comentario respecto de la muerte de su vecina (11). 
La configuración ficcional de la consciencia y lenguaje del niño se evoca, además, por medio de la transgresión del ordenamiento que se sirve de elementos temporales como organizadores del discurso escrito (Calsamiglia y Tusón 281). En la cultura escrita actual es de alta importancia la "correspondencia entre el orden lineal de los elementos en el discurso y el orden de referencia, el orden cronológico en el mundo al cual se refiere el discurso" (Ong 144). El alejamiento de lo anterior puede advertirse, en la serie de Paz, en secciones como la que mostramos a continuación. En ella, Papelucho presenta su "programa de vida". Comienza señalando que terminará su bachillerato a los 16 años, luego, que cuando tenga 10 será campeón de saltos mortales, a los 17 se casará, a los 18 predicará el evangelio y que morirá entre los 20 y 30 años (Papelucho 59). Ejemplos como este, evidencian la construcción de un fluir del pensamiento del niño, su relato se va configurando a modo de libre asociación, en el orden en que las ocurrencias emergen espontáneamente en la consciencia ficcional. Esta transgresión temporal potencia también la sensación de oralidad, la cual, como explica Ong, no busca necesariamente una coherencia secuencial lineal y exactamente cronológica en el discurso (144).

Por otra parte, de forma adicional a los temas de coherencia, la estructuración inusual o rupturista respecto de las convenciones escriturales y lingüísticas que favorecen la sensación de un habla y, por tanto, una consciencia infantil, se encuentran también a nivel de frases y oraciones. En dicha redacción se subvierten las funciones de elementos que por definición se utilizan con ciertos fines (presentados abajo en cursiva), dándoles un rol distinto. No obstante, es posible, en la mayoría de los casos, comprender la idea de los enunciados, como en los que a continuación se presentan:

Así que me acosté no más y la Zoila me trajo un pollito asado entero para mí y comido a dedo (Papelucho casi huérfano 40).

Cuando me encontraron en el 13 estaba mal de gravedad (...) (Papelucho en la clínica 19).

Mi felicidad de que los de la Banda no me hicieran burla, se iba destiñendo mientras se me agrandaba la congoja del hermano perdido (Papelucho mi hermano hippie 39).

Quienzá si ella me encontraría a mí con su olfato y mi olor" (¿Soy dix leso? por Papelucho 85). 
En el colegio hay montones de mala memoriados (Diario secreto de Papelucho y el marciano 8).

Nos centraremos en el último ejemplo. En la oración "En el colegio hay montones de mala memoriados", se advierte un uso, si bien no erróneo, algo singular a nuestra vista adulta acostumbrada a usanzas más convencionales como la siguiente: En el colegio hay montones de niños que tienen mala memoria. Esta rearticulación revela que, en la segunda parte de la oración compuesta, el sujeto se mezcla con el verbo y con el adjetivo. Es decir, en la alocución "mala memoriados" encontramos un sujeto implícito (alumnos), un verbo implícito (tienen) y un complemento adverbial del sujeto (mala memoria). Se evidencia también que se prescinde del elemento de la oración subordinada-adjetiva 'que': que tienen mala memoria. En resumen, en la expresión "mala memoriados" se reúnen la mayoría de los elementos que compondrían la segunda parte de la oración compuesta, si ésta estuviese guiada por una estructura morfosintáctica más convencional. En este uso liberado de las amarras de las convenciones, que además continúa generando una sensación de oralidad (por lo fresco, espontáneo y personal en la selección del léxico y su ordenamiento), avizoramos una estrategia de singularización del lenguaje. Las frases y oraciones arriba expuestas constituyen, en palabras de Shklovski, estrategias literario-estéticas que buscan "la liberación del objeto del automatismo perceptivo [que] se logra por diferentes medios" $(57,61)$. En este caso, el medio es la configuración morfosintáctica, la cual se busca singularizar, hacerse extraña, llamando la atención sobre sí misma. En esta operatoria se produce la liberación de la cual habla Shklovski, en tanto se desnaturalizan las formas más prototípicas de redactar una oración, cuando nos enfrenamos a la forma lúdica y contextual, en que el narrador utiliza la lengua. Esta estrategia de singularización del objeto estético busca que percibamos que aun cuando Papelucho utilice fórmulas u ordenamientos que suenen poco usuales, esto no constituye error, ni falta de comprensión de quien percibe, sino que representa una relación más vívida, personal y menos alienada con el lenguaje. El narrador no construye sus ideas por medio de las formas habituales disponibles en el repertorio de la lengua, las configura a partir de su inventiva e intuición, haciéndolas nuevas y propias. Así, Paz yergue estéticamente una infancia que se aleja de los imaginarios de limitación lingüística, otorgándole, al contrario, un poder de apropiación consciente y sagaz a esta esfera. 


\section{COLOFÓN: VALIDACIÓN LINGÜÍSTICO-LITERARIA DEL HABLA DE LA NIÑEZ}

A partir de lo expuesto en las secciones precedentes, observamos la configuración de un efecto de consciencia infantil, que se lleva a cabo, por una parte, a través de la constitución de un narrador altamente protagónico, que participa de las acciones que relata y que es autoconsciente de su función de escritor. Por otra parte, se articula por medio de un proceso de libre apropiación de la palabra, que constituye, en muchos casos, trasgresión en los usos lingüísticos de carácter multidimensional, operando en ámbitos tales como el léxico, semántico, morfosintáctico y discursivo, entre otros.

Como mostramos a lo largo de este trabajo, en la serie se visibiliza la falta, la confusión, el desconocimiento, el uso más contextual y creativo de la lengua. Por medio de estos elementos literario-lingüísticos se configura un efecto de liberación que, una y otra vez, busca escapar del yugo omnipresente de la norma lingüística. Esta operatoria pone de manifiesto la condición inherente de la lengua como sistema dinámico y complejo, atravesado por espacios de indeterminación, de puntos de fuga. De esta forma, la construcción lingüística de una consciencia infantil en la serie de Paz puede leerse en consonancia con la propuesta de Kristeva, en lo que refiere a la dimensión sémiotique del lenguaje.

En los años 70, Kristeva critica y se opone a las líneas disciplinares que conciben al lenguaje como sistema compuesto por unidades con significados fijos, como era el caso de la filología, o como entidad con una estructura identitaria de total coherencia; una unidad orgánica que se definía, según lingüistas comparativistas, por leyes que habrían cruzado históricamente las hablas nacionales (Kristeva 127). En contraste, la autora comprende el lenguaje como un sistema de significación que no puede limitarse al marco de una sola unidad o identidad, en tanto no puede desligarse de la ambigüedad, del error, de lo fragmentario e instintivo. Estas características no se relacionan, por lo tanto, únicamente con un estado subdesarrollado, psicótico o infantil del lenguaje, sino corresponden a una disposición natural del mismo. A una disposición sémiotique, una dimensión donde colapsa la función significante y se expresa la subjetividad de lo musical y el sinsentido, donde se quiebran los presupuestos socioculturales y sintácticos mismos. Esta dimensión sémiotique, que podría situarse paralelamente al orden de Lo Imaginario, se opone a la función symbolique entendida como aquella que busca la homogeneidad y la normatividad (Kristeva 133). 
La esfera sémiotique, que apela a la irreductibilidad de la experiencia humana dentro de un conjunto de normas y reglas, puede vislumbrarse en la lectura de la serie de Paz. En sus textos, la falta, el error, la confusión y el uso libre e inventivo de términos y expresiones ponen al descubierto la infranqueable parcialidad con que las palabras se acercan a lo que se busca comunicar, de manera que se requiere la creación de vocablos para aproximarse mejor a la intención expresiva del narrador. No hay palabra para connotar la fuerza, el impacto de lo que "cataclípticamente" quiere transmitir.

Si bien en distintos recursos literario-lingüísticos que se aprecian en la constitución de un lenguaje infantil se visibiliza una figura de niñez que se vincula al orden de Lo Imaginario, puede al mismo tiempo advertirse que la perspectiva de enunciación no construye dicho orden en tanto sitio de limitación. Al contrario, la infancia se articula como espacio lingüísticamente autosuficiente. Muestra de esta autosuficiencia es que las confusiones o desconocimiento no se presentan en la serie como una desventaja o dificultad. Al contrario, se erigen para constituir un habla idiosincráticamente infantil, la que se basa en la apropiación exploratoria y lúdica del lenguaje, proceso en que se singulariza, sacándolo del automatismo del que habla Shklovski. La perspectiva enunciativa tampoco sugiere que el niño presente problemas significativos de comprensión. Al contrario, se muestra que, aun cuando no maneje totalmente ciertos conceptos, puede comunicarse de forma efectiva, debido a que no solo se sirve de lo lingüístico sino también de la comprensión del contexto. Operan en este caso, tanto procesos comunicativos como cognoscitivos de índole interpersonal.

Por otra parte, no hay una propuesta en la serie respecto de la instrucción en el ámbito del lenguaje. En ninguna de las novelas se hace alusión a algún afán didáctico, que busque la mejora del desempeño lingüístico por parte de Papelucho.

En conclusión, puede sostenerse que la subjetividad lingüística del niño se establece ficcionalmente como un espacio de completitud, en tanto las formaciones lingüísticas erróneas o confusas se hipervisibilizan desde lo humorístico como instrumentos de expresión. Se da pie a la configuración de un imaginario de infancia que, a través de la creación de una consciencia lingüística ficcional, se libera de lo lingüísticamente reglamentario, reclamando los espacios de indeterminación en su habla íntima (conversación consigo mismo a través del diario). Una infancia que potencia el error, la confusión, lo creativo/inventivo como mecanismos vitales que subvierten la homogenización de las formas expresivas, que subjetivizan y, por lo tanto, 
hacen genuino y propio su hablar. Nos encontramos frente a una infancia con un empoderamiento lingüístico, un niño que espontánea y vigorosamente exige y hace suyo el derecho a hablar libremente, reclamando los sitios de indeterminación y la función poética del lenguaje en el día a día; desde el supuesto anonimato de su diario.

A partir de las formas en que se despliegan las estrategias literariolingüísticas en la serie de Paz, se pone de manifiesto la construcción de una infancia que efectivamente puede vincularse con el estadio lacaniano de Lo Imaginario, pero desde una propuesta enunciativa que dialoga con la idea de Kristeva. Su lenguaje se ampara en elementos que lo conectan con lo oral, con lo coloquial; ligado más bien a lo contextual y creativo que a lo convencionalmente correcto. Se constituye, así, un habla a partir de lo instintivo, espacio donde se despliegan las fuerzas incontrolables y desconocidas del origen inconsciente del lenguaje (Lacan 68), que posicionarían al narrador en la esfera de Lo Imaginario. No obstante, al mismo tiempo, hay un diálogo con el orden de Lo Simbólico.

La negociación y tensión con el orden de Lo Simbólico es visible a partir del conocimiento léxico, semántico y de géneros discursivos relativamente sofisticado que el narrador posee. Hemos dado cuenta de su conocimiento de patrones de formación y creación de palabras, tales como la derivación, entre otros. Entiende conceptos complejos como "amnesia", entiende y usa un amplio rango de léxico coloquial. Registra, comprende y parodia variedades diastráticas del español chileno (especialmente popular), con todo su espesor y riqueza cultural. De esta manera, se establece una idea de niñez que participa y transa con los códigos lingüísticos del mundo adulto, los cuales el niño utiliza y respeta en ciertas ocasiones, pero que, en la intimidad de su diario de vida, libera de las constricciones formales y deja fluir embebido por el poder expresivo que se nutre de sus pasiones fundamentales. En este tránsito, desdibuja y tensiona el rol normativizador, conectado con la figura de autoridad del padre como representante figurativo de la ley; aquel Orden Simbólico, que impone la función correctiva del lenguaje formal (Kristeva 135).

Este diálogo con el orden de Lo Simbólico se manifiesta, también, a través de la construcción de la plena consciencia infantil del narrador sobre la performatividad del lenguaje. Lo que se comunica gracias al establecimiento de una voz narrativa autoconsciente (self consciouss) (Both 163). Papelucho, constantemente hace referencia a sus propios procesos de escritura; es un niño que modifica conscientemente su léxico y su registro cuando está en un contexto sociocultural que discrepa del suyo, o en un contexto en que cierto 
tipo de lenguaje no es apropiado. El niño sabe, por ejemplo, que si crea una poesía sobre el papel higiénico no es apta en el ámbito escolar, pero sí aquella que versa sobre un héroe patriótico (Mi hermana Ji por Papelucho 52).

Se constituye, en consecuencia, una infancia que no solo habita el espacio de Lo Imaginario. La infancia que crea Paz es consciente y participante de las hablas de entornos culturales diversos, lo que se grafica por medio del uso del lenguaje coloquial y social dialógico. Así, a diferencia de un amplio número de narrativas para la infancia publicadas en Chile entre las décadas de 1940 y 1970, como se da cuenta en otro trabajo (Ibaceta, "Bodies and voices" 40-52), no solo se le entrega al niño un habla protagónica, sino que se valida y da espacio a este hablar en el contexto político y social de su época, sin confinársele únicamente a cronotopos domésticos, escolares y de fantasía aislados de los fenómenos socioculturales que aluden a sus contextos de producción.

La inclusión de las hablas del entorno (diversidades sociolectales), establece una visión de infancia que es testigo, que se interesa y vincula con los fenómenos socio-políticos. Esto es evidente en un texto como Papelucho detective (1957), cuya trama transcurre de manera importante en las "callampas". Dimos cuenta de cómo se busca visibilizar el habla de los pobladores y pobladoras. A partir de esta diversidad de hablas, es posible observar un diálogo con el contexto de producción que podría remitir a problemáticas asociadas a diversos factores socioeconómicos (particularmente laborales) y urbanísticos, entre otros, que en la década de 1950 se traducen en la instalación sustantiva de las llamadas "poblaciones callampas" en Santiago (Salazar 38, 176). Este diálogo con el contexto político y social se articula estéticamente en la serie, en gran medida, a través de la ironía estructural, que permite la creación de un personaje que se reviste de un halo de ingenuidad, con motivo de permitirle develar problemáticas sociales. El discurso vinculado a una crítica social en la serie es un fenómeno que, sin duda, se requiere abordar en extenso, en un trabajo futuro.

A partir de lo discutido a lo largo de este trabajo, podemos hacer una correlación entre una acción de liberación y complejización del imaginario de infancia por parte de Kristeva, así como por parte de Paz. Dicho de otro modo, Kristeva, en el momento en que sostiene que la disposición sémiotique es algo inherente a todo lenguaje, libera a la figura de la infancia como símbolo primero del orden de Lo Imaginario y la exime de su condición de sujeto lingüístico inacabado. Por su parte, por medio de la construcción de un lenguaje infantil, Paz vincula a la niñez con el orden symbolique y la sitúa 
como testigo, partícipe e interlocutora lingüística válida en el contexto político y social de su época, estableciéndose un habla infantil sin precedentes, que contrasta totalmente con las voces invisibles y/o subyugadas de los personajes infantiles presentes en la mayoría de la narrativa para la infancia en Chile entre los años 40 y 70 (Ibaceta, "Bodies and voices" 40-52).

Con este trabajo esperamos visibilizar la importancia que reviste la construcción discursiva de la niñez, particularmente las formas en las cuales se le da protagonismo a voces narrativas infantiles y las configuraciones lingüísticas que permiten la creación artístico-ideológica de un lenguaje y, por lo tanto, de una consciencia infantil. Al examinar las formas en que se ficcionaliza el lenguaje infantil, hemos buscado, siguiendo las propuestas de Susan Sontag, atender a una crítica menos prescriptiva, que permita observar la constitución y dinámicas de la obra de arte, sin reducirla a un mero conjunto de contenidos. En consecuencia, hemos intentado mostrar "cómo es lo que es (...)" (27). De ahí que hemos centrado nuestro análisis en la singularidad estética del lenguaje, que nos permite acercarnos a la articulación de imaginarios de niñez en la serie.

Por último, esperamos contribuir a potenciar el interés por el estudio de los textos de Paz, los cuales, si bien constituyen un hito literario y editorial desde la década de 1940, aún no reciben suficiente atención académica. De la mano de esto, nuestra intención es relevar un tipo de literatura que, en tanto fenómeno constitutivo del patrimonio cultural y como espacio inherentemente ligado a la construcción y legitimación (o subversión) de discursos ideológicos, requiere ser explorada.

\section{BIBLIOGRAFÍA}

Amaro, Lorena y Francisca Lange "Dossier: escrituras de infancia". Aisthesis 54 (2013): 239-242. Ariès, Philippe. Centuries of childhood. A social history of family life. Trad. Robert Baldick. New York: Vintage, 1962.

Bajtín, Mijaíl. Problemas literarios y estéticos. Trad. Alfredo Caballero. La Habana: Editorial Arte y Literatura, 1986.

Booth, Wayne C. The rhetoric of fiction. Chicago, London: The University of Chicago Press, 1961.

Bourdieu, Pierre. ¿Qué significa hablar?: economía de los intercambios lingüísticos. Trad. Esperanza Martínez. Madrid: Akal, 2008.

Bybee, J. L. Language, usage and cognition. Cambridge: Cambridge University Press, 2010. 
Calsamiglia, Helena y Amparo Tusón. "Modos de organización del discurso". Las cosas del decir: Manual de análisis del discurso. Barcelona: Editorial Ariel, 2001.

Cifuentes, Edgardo. "Marcas discursivas y narrativas del humor leve en Papelucho". Literatura y Lingüistica 24 (2011): 15-32.

“Angustia y humor en Papelucho de Marcela Paz". Logos: Revista de Lingüística, Filosofia y Literatura 25.2 (2015): 131-139.

Cohn, Dorrit. Transparent minds. Narrative modes for presenting consciousness in fiction. Chichester, West Sussex: Princeton University Press, 1978.

Colebrook, Claire. Irony. Oxford: Routledge, 2009.

Croft, William y D. Alan Cruse. Cognitive linguistics. Cambridge, U.K: Cambridge University Press, 2004.

Cross, July. Humour in contemporary junior literature. Oxford: Routledge, 2011.

Cruzat, Virginia. Marcela Paz, un mundo incógnito. Santiago: Editorial Universitaria, 1992.

Cunningham, Hugh. Children and childhood in western society since 1500. 2da. ed. Harlow: Pearson-Longman, 2005.

Crystal, David. A dictionary of linguistics and phonetics. 6ta. ed. Oxford and Cambridge (Mass., USA): Wiley-Blackwell, 2008.

Ducrot, Oswald y Tzvetan Todorov. Trad. Enrique Pezzoni. Diccionario enciclopédico de las ciencias del lenguaje. 2da. ed. Buenos Aires: Siglo Veintiuno, 2011.

Erman, Britt y Beatrice Warren. "The idiom principle and the open choice principle". Text 20.1 (2000): 29-62.

Frye, Northrop. Anatomía de la crítica. Trad. Edison Simons. Caracas: Monte Ávila Editores, 1991.

Fuguet, Alberto. "Papelucho Revisitado". El Mercurio, Abril 21 2007, Revista del Sábado, p. 18.

Goodenough, Elizabeth et al. Infant tongues: the voice of the child in literature. Detroit: Wayne State University Press, 1994.

Halliday, M. A. K. Spoken and written language. 1985. Oxford: Oxford University Press, 1989. "Spoken and written modes of meaning". Comprehending oral and written language. Eds. R. Horowitz y S. J. Samuels. San Diego: Academic Press, 1987. 55-82.

Hollindale, Peter. "Ideology and the children's book". Literature for children: contemporary criticism. Ed. Peter Hunt. London: Routledge, 1992. 18-40.

Hunt, Peter. Ed. Understanding children's literature. London: Routledge, 2005.

Hurst, Mary Jane. The voice of the child in American literature. Kentucky: The University Press of Kentucky, 1990.

Ibaceta, Isabel. "El cuerpo del niño en Papelucho de Marcela Paz: voz y cronotopo infantil". Discursos para infancia, adolescencia y juventud: reflexiones desde los estudios literarios. Santiago: Editorial Universitaria, 2016.

"Más allá de Papelucho: Marcela Paz, una propuesta literaria desconocida". Umbral: Literatura para Infancia, Adolescencia y Juventud 2.2 (2016): 4-23. 
"Bodies and voices in chilean children's literature: fifty year of silencing childhood (1920-1970)". Bookbird: A Journal of International Children's Literature 59.2 (2021): 40-52.

Jeftanovic, Andrea y María José Navia. Hablan los hijos: discursos y estéticas de la perspectiva infantil en la literatura contemporánea. Santiago: Cuarto Propio, 2011.

Joosen, Vanessa. Adulthood in children's literature. London: Bloomsbury Academic, 2018.

Kristeva, Julia. “D’une identité l'autre. Le suject du «langage poétique»”. Tel Quel 62 (1975): $10-27$.

Lacan, Jacques. Ecrits: the first complete edition in English. Trad. Bruce Fink et al. London/ New York: W.W. Norton \& Company, 2006.

Larraín, Ana María. Marcela Paz, una imaginación sin cadenas. Santiago: Editorial Universitaria, 2009.

Mills, Jean y Richard W. Mills. Childhood studies: a reader in perspectives of childhood. London: Routledge, 2000.

Myers, Mitzi. "Reading Rosamond reading: Maria Edgeworth's «wee-wee stories»". Infant tongues: the voice of the child in literature. Detroit: Wayne State University Press, 1994. 57-79.

Nikolajeva, Maria. "Imprints of the mind: the depiction of consciousness in children's fiction". Children's Literature Association Quarterly 26. 4 (2001): 173-187.

Aesthetic approaches to children's literature: an introduction. Maryland: Scarecrow Press, 2005.

Ong, Walter. Oralidad y escritura. Tecnologías de la palabra. Buenos Aires: Fondo de Cultura Económica, 2006.

Paz, Marcela. Papelucho. Santiago: Editorial Rapa-Nui, 1947.

Papelucho casi huérfano. 2da. ed. Santiago: Editorial del Pacífico, 1955.

Papelucho historiador. Santiago: Editorial del Pacífico, 1955.

Papelucho detective. Santiago: Editorial del Pacífico, 1957.

Papelucho en la clínica. Santiago: Editorial del Pacífico, 1959.

Papelucho perdido. Santiago: Editorial Pomaire, 1962.

Mi hermana Ji por Papelucho. Santiago: Editorial Pomaire, 1965.

Papelucho misionero. Santiago: Editorial Pomaire, 1966.

Diario secreto de Papelucho y el marciano. Santiago: Editorial Pomaire, 1968.

Papelucho en vacaciones. Santiago: Editorial Pomaire, 1971.

Papelucho: mi hermano hippie. Barcelona: Editorial Pomaire, 1971.

¿Soy dix leso? por Papelucho. Santiago: Editorial Universitaria, 1974.

Peña Muñoz, Manuel. "Marcela Paz y "Papelucho”. Historia de la literatura infantil chilena. 2da. ed. Santiago: Andrés Bello, 2009. 70-72.

Rahn, Suzanne. "The changing language of black child characters in American children's books". Infant tongues: the voice of the child in literature. Detroit: Wayne State University Press, 1994. 225-228. 
Ricou, Laurence. Everyday magic: child language in Canadian literature. Vancouver: University of British Columbia Press, 1987.

Rojas Flores, Jorge. Historia de la infancia en el Chile republicano (1810-2010). Santiago: Ediciones de la JUNJI, 2016.

"Los niños y su historia: un acercamiento conceptual y teórico desde la historiografia". Pensamiento crítico 1 (2001): 1-39. Enero 2012. http:www.archivochile.com

Rudd, David. “Theorising and theories: how does children's literature exist?" Understanding children's literature. Ed. Peter Hunt. London: Routledge, 1999. 15-29.

Reading the child in children's literature: an heretical approach. Basingstoke, United Kingdom: Pelgrave Macmillan, 2013.

Salazar, Gabriel. Movimientos sociales en Chile: trayectoria histórica y proyección politica. Santiago: Uqbar Editores, 2014.

Shklovski, Viktor. "El arte como artificio". Teoría de la literatura de los formalistas rusos. Ed. Todorov Tzvetan. Trad. Ana María Nethol. Buenos Aires: Siglo Xxi, 1978. 55-70.

Sontag, Susan. Contra la interpretación y otros ensayos. Trad. Horacio Vázquez R. Barcelona: Penguin Random House, 2016.

Stange, Ulrike. Emotive interjections in British english: a corpus-based study on variation in acquisition, function and usage. Amsterdam: John Benjamins Publishing Company, 2016.

Stephens, John. "Narratology". The Routledge companion to children's literature. Ed. David Rudd. Oxford: Routledge, 2010. 51-62.

Subercaseaux, Bernardo. Historia del libro en Chile (alma y cuerpo). 2da. ed. Santiago: LOM Ediciones, 2000.

Tesnière, Lucien. Éléments de syntaxe structurale. 2da ed. Paris: Klincksieck, 1976.

Vihman, Marilyn. Phonological development: The first two years. Oxford: Wiley Blackwell, 2014.

Wall, Barbara. The narrator's voice: the dilema of children's fiction. London: McMillan, 1990.

Wells, Gordon. The meaning makers: learning to talk and talking to learn. Bristol: Multilingual Matters, 2009.

Zipes, Jack. Fairy tales and the art of subversion. Oxford: Routledge, 2007. 